\title{
Iconografía de las tabletas para inhalar sustancias psicoactivas de la zona de San Pedro de Atacama, norte de Chile
}

Manuel C. TORRES ${ }^{1}$

\begin{abstract}
RESUMEN
Los objetivos de este trabajo son: 1) clasificar la iconografía de las tabletas para inhalar sustancias psicoactivas de la zona de San Pedro de Atacama; 2) definir cada elemento de posible valor iconográfico, establecer sus variantes y asociaciones más frecuentes, y 3) colocar los motivos representados en las tabletas dentro del contexto de imágenes relacionadas con el uso de alucinógenos en Sudamérica.
\end{abstract}

\section{Introducción}

Las investigaciones acerca de la utilización de alucinógenos de origen vegetal por grupos indígenas sudamericanos son cada vez más frecuentes. Estos estudios se basan, primariamente, en información etnográfica, consecuentemente la influencia de estas substancias en la formación y desarrollo de estructuras de creencias en las sociedades prehispánicas es un aspecto poco conocido. En estas culturas los agentes psicotrópicos pueden haber sido parte importante de los esfuerzos por establecer contacto con lo "sobrenatural", y en su subsecuente manipulación para alcanzar fines socioculturales. Las tabletas reunidas en la colección del Museo Arqueológico R. P. G. Le Paige, debido a su limitada distribución geográfica, nos permiten observar el desarrollo de un complejo sistema iconográfico en relación directa con el uso de alucinógenos en una cultura prehispánica en específico.

Históricamente se constata la existencia de prácticas insuflatorias desde los primeros documentos de la Conquista. Cristóbal Colón ya ca. 1496 escribe:

"Idolatría u otra secta no he podido conocerles, aunque todos sus reyes que son muchos, tanto en la Española como en Tierra Firme, tienen una casa para cada uno de ellos... en la cual no hay otra cosa sino imágenes de madera... que ellos llaman cemíes...

1 Florida International University, Visual Arts Department, Tamiami Campus, Miami, Florida 33199, ESTADOS UNIDOS.
En esta casa tienen una mesa bien labrada... de forma redonda como un tajador, en la cual hay unos polvos, que ponen en la cabeza de dichos cemíes, haciendo cierta ceremonia; después con una caña de dos ramos que se meten en la nariz aspiran este polvo" (Pané 1974: 88).

Como vemos por lo precedente, en estas palabras escritas por Colón durante su segundo viaje (14931496) se menciona específicamente el uso de una tableta y de un tubo como parte de la parafernalia de insuflación.

Otro de los documentos en mencionar el uso de una tableta es el del fraile Jerónimo Ramón Pané, quien efectúa la redacción de su manuscrito $c a$. 1494-1498. Pané se refiere por primera vez al polvo psicoactivo con un nombre aborigen:

“... la cohoba es un cierto polvo, que ellos toman a veces para purgarse y para otros efectos que después se dirán. Esta la toman con una caña de medio brazo de largo, y ponen un extremo en la nariz y el otro en el polvo; así lo aspiran por la nariz y esto los hace purgar grandemente" (Pané 1974: 30).

Fray Bartolomé de Las Casas también se refiere a la inhalación de un polvo psicoactivo por los Taíno de las Antillas Mayores. Las Casas, quien residió en las Antillas de 1502 a 1514, nos brinda una descripción de una tableta y un tubo:

"Tenían hechos ciertos polvos de ciertas yerbas mиy secas y bien molidas, de color canela...; estos ponían en un plato redondo, no llano, sino un poco algo combado u hondo, hecho de madera, tan hermoso, liso y lindo que no fuera muy más hermoso de oro o de plata; era casi negro y lucio como de azabache. Tenían un instrumento de la misma madera y materia, y con la misma polideza y hermosura; la hechura de aquel instrumento era del tamaño de una pequeña flauta, de los dos tercios de la cual en adelante se abría por dos canutos huecos... Aquellos 
dos canutos puestos en ambas a dos ventanas de las narices, y el principio de la flauta, digamos, en los polvos que estaban en el plato, sorbían con el huelgo hacia dentro... Estos polvos y éstas ceremonias o actos se llamaban cohoba, la media silaba luenga en su lenguaje; alli hablaban como en algarabía, o como alemanes, confusamente no se que cosas y palabras" (Las Casas 1909: 445).

Las descripciones de Colón, Pané y Las Casas, conjuntamente con la abundante evidencia etnográfica (p.e., Spix y Martius 1831: Pl. 36-6; Herndon 1853: 318; Polykrates 1960: Abb. 2-4, 8; Frikel 1961:3, 4), determinan definitivamente el carácter de las tabletas y los tubos. Se anota lo previo debido que a principios de siglo su uso fue sujeto de las más fantásticas explicaciones (p.e., Ambrosetti 1899: 44; Lehmann-Nitsche 1902: 10-11), y muy recientemente el arqueólogo argentino Alberto Mario Salas (1945: 205) pone en duda la función insuflatoria de estos objetos.

El uso de una tableta como parte integral del ajuar insuflatorio tiene una amplia distribución en Sudamérica. Hasta ahora se han encontrado tabletas tan al norte como la Sierra Nevada de Santa Marta en Colombia (Reichel-Dolmatoff 1972: 67), y tan al sur como Guandacol, La Rioja, Argentina (Alanís 1947: 10, 11) y Coquimbo, Chile (G. Castillo com. pers.). Su distribución temporal es también de gran amplitud. Las tabletas de mayor antigüedad conocidas hasta ahora proceden de yacimientos en la costa de Perú pertenecientes al Período Precerámico Tardío (Bird 1948; Engel 1963). La utilización de la tableta continúa hasta nuestros días, su uso fue observado entre varios grupos de la cuenca del Amazonas (Frikel 1961). Pero es en la zona de San Pedro de Atacama donde ocurre la mayor concentración de estos artefactos en un contexto arqueológico.

\section{Iconografía de las tabletas de San Pedro de Atacama}

Al revisar las notas de excavaciones mantenidas por Gustavo Le Paige, con el propósito de aislar las tumbas con tabletas para la inhalación de polvos psicoactivos, he constatado que él recupero 511 tabletas en 40 sitios. De éstas, 454 se encuentran depositadas en las colecciones del Museo Arqueológico R. P. G. Le Paige de San Pedro de Atacama. Los sitios de esta área que tienen una mayor cantidad de tabletas son: Quitor 6 con 123 tabletas en 110 tumbas, de un total de 375 excavadas; Coyo Oriente con 73 tabletas procedentes de 65 tumbas, de un total de
216 excavadas; y Quitor 5 con 67 tabletas en 50 tumbas, de 218 excavadas.

La mayoría de las tabletas están asociadas con cerámica de los tipos Negro Pulido y Negro Casi Pulido, alfarería que define la fase conocida como San Pedro II. En sólo tres ocasiones hay tabletas asociadas al tipo Rojo Violáceo, o sea la Fase III (p.e., la tumba nº 3942 de Coyo Oriente). En cinco casos se han encontrado tabletas en contextos con cerámica tipo Rojo Pulido (San Pedro I), de éstos, cuatro están también asociados con el tipo Negro Pulido. En sólo una ocasión, la tumba $\mathrm{n}^{\circ} 3187$ de Quitor 8, con Rojo Pulido y ningún otro tipo de cerámica; desafortunadamente esta tableta no se encuentra en las colecciones del museo. No podemos concluir, por el momento, que las tabletas son una característica exclusiva del Período Medio (San Pedro II). Aparentemente, Le Paige prefería excavar las zonas de los cementerios en que encontraba cerámica de los tipos Negro Pulido y Negro Casi Pulido. Esto es evidente en el cementerio do Quitor 6, en el cual la zona intensamente excavada es la central, y no los extremos donde parecen encontrarse los tipos Rojo Pulido y Rojo Violáceo.

La iconografía de las tabletas de San Pedro de Atacama es de una gran variedad, siendo más complejas esas que exhiben rasgos del llamado estilo tiwanaku. Para los propósitos de este trabajo presentaré primero las tabletas con elementos tiwanacoides. Este orden de presentación no implica una sucesión cronológica. Esto se debe a que existen tabletas con rasgos Tiwanaku y otras que no demuestran influencia del estilo altiplánico, asociadas con los tres tipos cerámicos más frecuentes en San Pedro de Atacama. Aparentemente estas dos corrientes, por así llamarlas, coexisten en el tiempo y no se suceden de una manera lineal.

Los temas iconográficos básicos en las tabletas de esta zona podrían clasificarse en 16 conjuntos de motivos con sus respectivas variables:

1) Figura frontal con dos cetros (2183 de Quitor 5; 3582 de Quitor 6; 4093 de Coyo Oriente).

2) Figura frontal emanando rayos (1618 Sequitor Alambrado Oriental; 1994 de Quitor 5; 4010 de Coyo Oriente).

3) Figura de perfil genuflexa (4008 y 4141 de Coyo Oriente). 
4) Figura alada (3380 Quitor 5; 3963 Coyo Oriente).

5) Figura con rasgos de felino (2189 y 2235 de Quitor 5).

6) Figura con brazos sobre el pecho (3944 y 5351 de Coyo Oriente).

7) Antropomorfos:

a) Humanos sin otros rasgos (2800 Quitor 6; 3975 de Coyo Oriente).

b) Figura femenina (1445 Yaye 1; 3236 Quitor 9).

c) Figura con apéndice cefálico cilíndrico (2108 Quitor 5: 2621 Quitor 6).

d) Figura reclinada sobre extensión planiforme (1702 Sequitor Alambrado Oriental).

e) Humano decúbito prono (1660 Sequitor Alambrado Oriental; 2477 Quitor 6).

f) Humano decúbito supino (sólo una tableta, sin número ni procedencia).

g) Cabeza(s) humana en relieve (2046 Quitor 5; 2811 Quitor 6).

8) El Decapitador o Sacrificador (1171 Tchecar; 2196 de Quitor 6; 4779 Solcor Nueva Población).

9) Felinos (sin rasgos Tiwanaku):

a) Zoomorfo:

a1) Relieve sobre extensión planiforme irregular (3531 Quitor 6; 4383 Toconao Oriente).

a2) Cabeza(s) en mango (1184 Tchecar; 2702 Quitor 6).

a3) Felino rampante (3647 Quitor 6).

b) Individuo con rasgos de felino (3688 Quitor

2).

c) Dobles o alterego (2077 Quitor 5; 2443 Quitor $6)$.

10) Aves:

a) Cóndor (1787 Catarpe 2; 4850 Tchilimoya).

b) Otras falcónidas (halcones?) (3605 Quitor 6; 4027 Coyo Oriente).

11)Camélidos (1636 Sequitor Alambrado Oriental; 1816 y 2317 Catarpe 2).

12) Ofidios (3662 Quitor 6; 5383 Coyo Oriente).

13)Peces (1647 Sequitor Alambrado Oriental).

14) Armadillo (1300 Sequitor Alambrado Oriental).

15) Diseños no figurativos (1230 y 3689 de Quitor 2).

16) Extensión planiforme sin decoración (2094 Quitor 5; 3618 Quitor 6).
Tabletas con rasgos Tiwanaku

Sólo han sido considerados como rasgos Tiwanaku esos temas y motivos que tienen su equivalente directo en otras expresiones del "estilo" boliviano. Con este criterio se encuentran en San Pedro de Atacama 41 tabletas tipo Tiwanaku, en las que se expresan seis temas o conglomerados de motivos. Estos son: personaje frontal con dos cetros que aparecen en cinco tabletas, y que se relaciona directamente con otro tema, una figura frontal emanando rayos que aparece en cuatro tabletas. Este tipo de personaje frontal es visto, por ejemplo, en la figura central de la llamada Puerta del Sol (Posnansky 1945: vol. 1: Pl. XLVII) y en otros objetos identificados con el estilo. El tercer tema, la figura genuflexa mirando hacia arriba, es el tema tiwanacota más frecuentemente representado. Ocurre en nueve ocasiones en las tabletas del museo, y puede ser el tema Tiwanaku más antiguo en la zona, pues en dos ocasiones está asociado a cerámica del tipo Rojo Pulido (tumbas 3223-24 y 3229-30 de Quitor 8). Figuras genuflexas pueden ser vistas, por ejemplo, en el dintel de la calle Linares (Posnansky 1945: vol. 2: Fig. 140a), y en una tableta de Niño Korín en Bolivia (Wassén 1972: Fig. 5). Este tema parece aún tener una mayor antigüedad, ya que representaciones de este tipo aparecen en cerámica Pucara (Posnansky 1957: Pl. LVI.B).

Las figuras aladas (cinco tabletas), los personajes con atributos de felino (cinco tabletas) y la figura frontal con los brazos sobre el pecho (tres tabletas) son otros de los temas de influencia Tiwanaku. Aparte de estos seis temas se observa la influencia Tiwanaku en varias de las tabletas con personajes que portan un hacha y una cabeza, el llamado Sacrificador o Decapitador (2189 y 2196 de Quitor 5). También hay casos únicos, como la tableta sin número reproducida en la Figura 1, y la procedente de la tumba 5381 de Coyo Oriente, en la que un ave devora los ojos de un ser humano.

Los elementos Tiwanaku son 26, que se manifiestan en los seis temas o conglomerados de motivos mencionados anteriormente. A continuación se enumeran estos elementos individuales, se señala su frecuencia y asociaciones, así como su representación en otras áreas culturales. 
1.

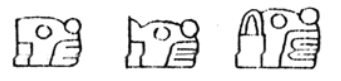

El elemento llamado "cabeza de felino" aparece en 21 ta-

bletas. En siete ocasiones sirve de terminación inferior de cetro (p.e., 4008 Coyo Oriente), en ocho casos está asociado con el elemento escalonado (p.e., 2196 Quitor 5; 3613 Quitor 6). Este motivo es de frecuente representación en objetos del sitio de Tiwanaku, incluso en una de las pocas tabletas procedentes de este centro urbano (Wassén 1967: Fig. 30). Su identificación como cabeza de felino si la comparamos con la de los felinos rampantes tallados en bajo relieve en una tableta del Museo de San Pedro de Atacama (ver Figura 1), es obvia.

2.

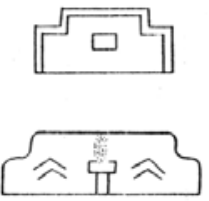

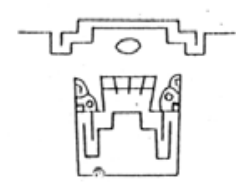

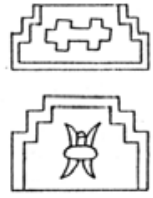

El motivo escalonado está representado en 19 tabletas (p.e., 3649 Quitor 6; 3706 Quitor 2; 4008 Coyo Oriente), en unas 10 variaciones. Este elemento exhibe frecuentemente proyecciones laterales: en once casos la "cabeza de felino", en seis por el elemento "cabeza de pez" (ver abajo), y en otra ocasión por el motivo "cabeza de ave" (ver abajo). En un solo caso, la tableta 4010 de Coyo Oriente, el elemento escalonado aparece sin proyecciones laterales. En varias tabletas el elemento escalonado encierra o contiene otro motivo. Pero uno de estos es de particular importancia, pues se repite, con ligeras variaciones, en siete tabletas. Sus variables son las siguientes:

3.

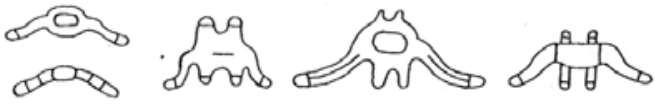

En las tabletas el elemento escalonado sirve como una base o plataforma sobre la cual acontece una acción; como por ejemplo actos de decapitación (tabletas 1994 y 2196 de Quitor 5), o figuras en genuflexión (p.e., la tableta 4141 de Coyo Oriente). Existe la posibilidad de que el motivo dentro del elemento escalonado señale el sitio apropiado para la acción representada, o bien, califique o modifique el acto, hecho o mito tallado sobre la plataforma escalonada.
4. (9)

Una barra terminada en uno o dos círculos concéntricos es un elemento representado en 17 tabletas, y cumple varias funciones. En 10 casos sirve como pendiente de codo (p.e., 4141 y 5351 de Coyo Oriente), en cuatro representa los rayos emanando de una figura heliomorfa (p.e., 1994 Quitor 5) y en otras cuatro ocasiones forma parte de coronas (p.e., 3944 y 4141 de Coyo Oriente). En varias ocasiones dos círculos concéntricos sirven como indicadores de piel de felino (ver Figura 1).

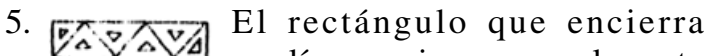 una línea en zigzag es un elemento} representado en 17 tabletas. Se debe señalar su representación en once cetros (p.e., 3380 Quitor 5; 4141 Coyo Oriente), en los cuales está asociado al elemento ondulado tripartita (ver abajo) en ocho ocasiones. Aparece cinco veces en la vestimenta de los personajes, cuatro en coronas, y en tres casos como mandíbula inferior. Este motivo es visto repetidamente en otros objetos Tiwanaku, entre otros el ya mencionado dintel de la calle Linares (Posnansky 1945: vol. 2: Fig. 140a), y también en tejidos de estilo Tiwanaku (Sawyer 1963: Fig. 1c).

6. El elemento ondulado tripartita está ref 7 . 4141 Coyo Oriente), en ocho de las cuales sirve de término superior de cetro en conjunción con el rectángulo conteniendo líneas en zigzag. Este motivo es de común representación en objetos con decoración tipo Tiwanaku. Es visto no solo en la escultura del sitio del altiplano, sino también en tejidos de este estilo (Sawyer 1963: 166), y anteriormente en cerámica procedentes de Pucara (Posnansky 1957: Pl. LVI.B). Referente a este motivo se debe anotar su asociación en varias ocasiones con fuego o llamas. El caso más directo es el de un tejido, supuestamente de Pisco, estudiado por Conklin (1971: Fig. 1). En este manto, cuya figura central recuerda al personaje de la Puerta del Sol, se encuentran dos individuos en cuclillas, uno frente al otro, envueltos en el acto de hacer fuego. Del palo que uno de ellos aparentemente frota, surge el elemento ondulado tripartita en representación de fuego o llamas. Además, entre las tabletas para alucinógenos de San Pedro de Atacama existen 21 que fueron usadas para hacer fuego en varias ocasiones. Principalmente la tableta procedente de la tumba 3944 de Coyo Oriente (Figura 2), la cual exhibe dos orificios producidos por esta acción, uno de ellos en el centro del elemento escalonado. En esta tableta el motivo ondulado tripartita está 
representado tres veces, en una de ellas sobre la plataforma escalonada, a los pies de la figura alada (idéntica situación puede ser observada en la tableta 2742 de Quitor 6). Podemos entonces sugerir una asociación indeterminada entre el acto de hacer fuego y la insuflación de sustancias psicoactivas en San Pedro de Atacama.

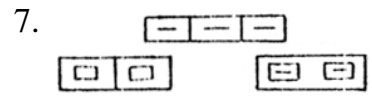

Este elemento está representado, en las tres variaciones indicadas, en 15 tabletas (p.e., 4008 y 4141 de Coyo Oriente); en seis casos aparece como corona de felino. El mismo motivo aparece en las coronas de las figuras laterales de la Puerta del Sol, y entre los diseños incisos que cubren la figura monolítica conocida como el Idolo Gigante (Posnansky 1945: vol. 2: Fig. 113a). Debe mencionarse la tableta 1945 de Quitor 5, en la cual este elemento se repite, alternando con el rectángulo conteniendo líneas en zigzag, alrededor del borde de la cavidad.

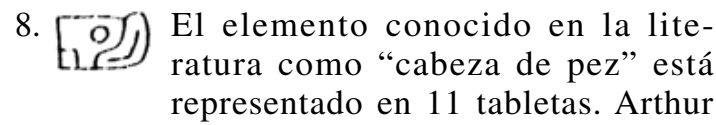
Posnansky (1945: vol. 2: Fig. 115) reproduce en su trabajo sobre Tiwanaku una foto del pez boga (Orestia) del lago Titicaca, que confirma definitivamente la identidad do este motivo. La "cabeza de pez" aparece en varias ocasiones como apéndice lateral de plataformas escalonadas (p.e., 3944 y 4008 de Coyo Oriente), o como parte de coronas (p.e., 5351 de Coyo Oriente).

9. Este motivo forma la banda que rodea la cara del personaje central de la Puerta del Sol. Aparece teniendo la misma función en la tableta procedente de la tumba 1994 de Quitor 5 (dibujo en Le Paige 1965: Lám. 59)² , donde está directamente asociado a dos motivos "cabeza de pez". Compone la faja, o cinturón, y la corona del personaje de la tableta 3706 de Quitor 2. También es representado cuatro veces en la base de una especie de mesa que lleva encima posibles motivos fitomorfos, que es parte de una representación del tema de la decapitación (tableta 2189 de Quitor 5). Dos probables variaciones pueden ser esas incisas el traje del individuo con rasgos de felino en la tableta 4049 de Coyo Oriente, y en esa con un personaje ornitomorfo procedente de la tumba 2742 de Quitor 5.

\footnotetext{
2 Dicha figura tiene errores.
}

10. 鸟

La "cabeza humana" aparece en siete tabletas. Parece ser importante su función como terminación inferior de cetro, en asociación con el rectángulo que contiene líneas en zigzag como cuerpo de cetro (posición intermedia), y el elemento ondulado tripartita como terminación superior (3229 de Quitor 8; 3380 de Quitor 5; 3613 de Quitor 6). También está representado en cuatro ocasiones en la vestimenta y otras en la corona del personaje con dos cetros de la tableta 4093 de Coyo Oriente. Este elemento tiene una gran antigüedad pues aparece en cerámica Pucara y en un tejido de Arica fechado en el siglo seis antes de nuestra era.

11. Este motivo aparece en siete tabletas, donde su representación está limitada al antebrazo de figuras con colgante de codo que portan un cetro (p.e., 4008 y 4141 Coyo Oriente).

12. ब응 Este elemento fue identificado por Posnansky (1945) como la versión frontal del motivo "cabeza de pez", pero sus argumentos en este caso, como en tantos otros, son demasiado especulativos. En todo caso este motivo aparece en seis tabletas, en diferentes funciones y posiciones relativas dentro de la estructura de la tableta (p.e., 4093 Coyo Oriente).

13. FO ح. La "cabeza de ave" es representada en seis tabletas. Este motivo, frecuente en la escultura de Tiwanaku, aparece también en una de las tabletas de piedra de este sitio (Uhle 1912: Fig. 15), y en una de madera procedente de Niño Korín, Bolivia (Wassén 1972: Fig. 9).

14. 幵 †十7 Este elemento aparece en seis tabletas, y en cinco de éstas forma parte de coronas (p.e., 3613 de Quitor 6). En la tableta 4093 de Coyo Oriente aparece encima de la plataforma escalonada. Este motivo es muy similar al elemento ondulado tripartita, pero se distingue de éste por la rigidez y regularidad de sus partes, que son cruzadas por una línea horizontal continua, y por su variante cuatripartita (p.e., tableta 2742 de Quitor 6).

15. ए El semicírculo con tres o más incisiones está representado en cinco tabletas. Este motivo parece servir como indicador de cóndor, debido a su representación en el cuello de personajes ornitomorfos, como es el caso de la tableta 2742 de Quitor 6. También está inciso en el cuello de la 
figura genuflexa con rostro de felino en la tableta procedente de la tumba 4141 de Coyo Oriente. Esta yuxtaposición felino-ave es frecuente en la iconografía relacionada con el uso de alucinógenos, y se discutirá más adelante.

16. 㽗

Este elemento aparece en una sola tableta de la zona de San Pedro de Atacama (4049 Coyo Oriente), en la que se repite siete veces. Es un motivo poco frecuente en la iconografía Tiwanaku. Posnansky (1957: Pl. XLI.C) reproduce un recipiente de cerámica de Tiwanaku en el cual este elemento es repetido seis veces. Este motivo parece adquirir importancia en los grandes recipientes de cerámica procedentes del sitio de Pacheco, cerca de Nazca (Perú), encontrados por Tello en 1927; estos tinajones pertenecen a la más temprana intrusión del estilo Wari en la tradición Nazca (Kubler 1975: 311, Pl. 174b; Posnansky 1957: Pl. LVIII). Estas vasijas exhiben una fusión del estilo Tiwanaku, con sus rígidas y geométricas formas, con otro más orgánico y descriptivo, una fusión que también es evidente en esta tableta.

17. También en la tableta 4049 de Coyo Oriente está representado este elemento, aparentemente una forma vegetal que pudiera interpretarse como maíz. Este motivo también ocurre en los tinajones de Pacheco previamente mencionados, donde está asociado, como en esta tableta, al motivo anterior. Este elemento parece ser una de las raras representaciones fitomorfas en las tabletas para alucinógenos.

18.<smiles>O1C2O[Ge]12</smiles><smiles></smiles>

Este elemento, en sus dos variables, aparece solo en dos tabletas (4093 y 5351 de Coyo Oriente). Su representación es poco frecuente, una de estas raras ocasiones puede ser vista en los ojos de los personajes con cabeza de cóndor que forman la fila del medio de las figuras laterales de la Puerta del Sol.

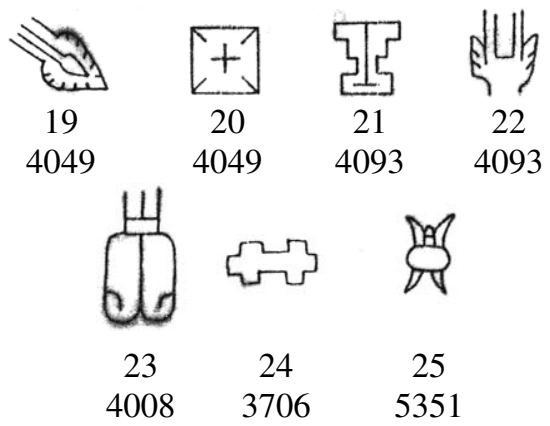

Existen otros siete elementos, todos excepto uno de Coyo Oriente, que aparecen en sólo una tableta. Es notable la tableta 4049 en la que están representados dos de estos motivos únicos, además de los dos $\left(\mathrm{n}^{\mathrm{os}} 16,17\right)$ previamente mencionados.

26.

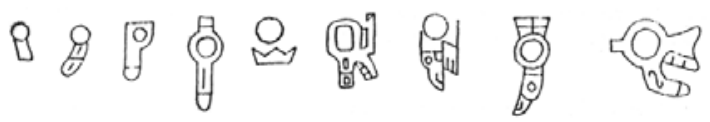

Las decoraciones alrededor de los ojos son muy variadas, y en algunos casos incluyen varios de los elementos enumerados anteriormente.

La organización de todos estos elementos en un conglomerado, o unidad coherente, que exprese los temas básicos Tiwanaku, puede que obedezca a ciertos patrones estructurales. Estos podrían estar relacionados con: 1) tipo y forma de asociación, esto es, cuáles motivos se encuentran juntos y en qué orden:

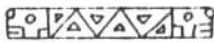

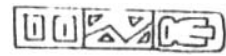

2) localización, en que objeto, humano o animal, se encuentra representando cada motivo en específico, y 3) posición relativa de los varios elementos. Por ejemplo, las representaciones de cetros en las tabletas siempre siguen el mismo esquema. El cetro está compuesto de tres partes variables: la terminación inferior y la superior, y el cetro propiamente dicho.
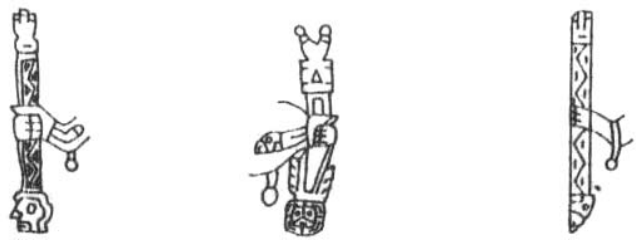

Otras posibilidades expresivas similares existen en la posición del motivo dentro del cuerpo de un personaje, o sea, como falda, cinturón, colgante de codo, ornamento del antebrazo o alrededor de los ojos, y sobre todo en las coronas:
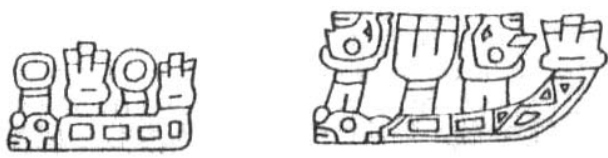

Entonces, puede que el tipo y forma de asociación, la representación de un elemento de cetros, coronas, 
plataforma escalonada, o dentro del cuerpo de un personaje, más su posición relativa dentro de cada uno de éstos, califique y modifique el significado de cada motivo en particular.

\section{El decapitador o sacrificador}

Un tema de frecuente representación en las tabletas es el del decapitador. Generalmente consiste de un ser humano con rasgos zoomorfos que porta un hacha y una cabeza trofeo. El personaje decapitador está representado en 11 tabletas de ésta (p.e., 2189 y 2196 de Quitor 5; 4779 Solcor Nueva Población), donde ocurre además en varios tubos y espátulas. Este tema es también común en las tabletas del área de Calama-Caspana-Toconce como, por ejemplo, esa reproducida por Oyarzún (1931: Fig. 10) que es ornamentada por dos personajes sacrificadores. Este tema es además visto en un tubo del sitio de Dupont publicado por Núñez (1964) en un estudio sobre el Sacrificador.

La relación del equipo insuflatorio con el concepto de la decapitación existe también en un contexto arqueológico, aparte de su directa representación en las tabletas y los tubos. En la tumba 2512-17 de Quitor 6 Le Paige (1964: 66-68) encontró cuatro cuerpos decapitados con las cabezas envueltas en un solo lienzo, colocadas a sus pies. Una tableta con cuatro figuras antropomorfas estaba en directa relación con los cuatro cadáveres. Todo esto parece indicar una posible relación entre los actos de decapitación y la insuflación de agentes psicoactivos. La importancia del Decapitador en esta zona se acentúa por su representación en el arte rupestre del desierto de Atacama. En el área de San Pedro de Atacama son notables los petroglifos del río Chuschul o Salado, afluente del río San Pedro, donde están representados individuos que portan cabezas trofeo. Representaciones del Decapitador también se encuentran en los petroglifos del cañón del Loa Superior (Mostny y Niemeyer 1983: Figs. 29, 122).

La presencia de este tema, lo mismo en tabletas Tiwanaku o en otras que no exhiben rasgos de este estilo, ya sea en San Pedro o en el valle del Loa, atestiguan su importancia y amplitud temporal. Debemos añadir que éste es un tema panandino que encuentra expresión en todo tipo de formas y artefactos, no solo en el ajuar insuflatorio y en el arte rupestre. El Decapitador es frecuentemente representado, por ejemplo, en la cerámica de Pucara, los tejidos de Paracas, la escultura monumental de San Agustín y en la metalurgia Wari.

Antes de concluir la discusión del tema del Decapitador se debe llamar la atención acerca de una serie de imágenes zoomorfas que aparecen en varias tabletas (p.e., 1171 Tchecar; 4779 Solcor Nueva Población) de este tipo. Estas figuras han sido identificadas como felinos, hombres murciélagos (Le Paige 1964) y hasta vampiros (Lehmann-Nitsche 1902). Si se observan detenidamente (ver Figura 3) es obvio que ni las fauces tan prominentes, ni las puntiagudas orejas, ni la nariz, son las de un felino o murciélago. Sin embargo, cuando se comparan las imágenes de esas tabletas con la de zorros vemos que las fauces, orejas y nariz se asemejan más a éstos que a felinos o murciélagos. Representaciones de este tipo en las tabletas se relacionan exclusivamente con el tema de la decapitación. A esto se puede añadir que el zorro todavía forma parte del folklore de la zona, y que aún se transmiten oralmente múltiples historias de sus trucos y fraudes, en las que casi siempre es un perdedor (Munizaga 1958: 47-50).

\section{Felinos}

Imágenes felínicas son de gran importancia en las tabletas en toda Sudamérica, tanto en esas encontradas en los Andes en contextos arqueológicos, como en las tabletas etnológicas de la cuenca del Amazonas (p.e., Polykrates 1960: Abb. 1, 4). Además de las representaciones en estilo Tiwanaku, la iconografía felínica puede ser subdividida en tres categorías: a) zoomorfos, b) complejo de transformación en felino, y c) doble o alter-ego.

Las representaciones zoomorfas son muy frecuentes y pueden a su vez subdividirse en tres categorías. La primera incluye las figuras en relieve sobre extensiones planiformes irregulares, que son vistas en nueve tabletas (p.e., 1680 de Sequitor Alambrado Oriental; 3531 de Quitor 6). La segunda categoría incluye las tabletas con una o más cabezas de felinos talladas en los apéndices o mangos, caso que ocurre en 21 tabletas (p.e., 1194 Tchecar; 1560 Yaye 3; 3236 Quitor 9). La tercera subdivisión es la de felino(s) rampante, que es una ocurrencia relativamente rara (ver Figura 1; también la tableta 3647 de Quitor 6).

Los individuos transformados en felinos o usando máscaras aparecen muy frecuentemente (p.e., 3688 de Quitor 2). La definición básica del tema de la transformación es la representación de un ser humano 
que ha adquirido rasgos de felino, o lleva una máscara con dichos rasgos. Máscaras de este tipo han sido encontradas en contextos arqueológicos en el norte de Chile. Grete Mostny (1958: 383, Figs. 2 y 3) reproduce dos máscaras de madera procedentes del valle de Lluta (I Región) y de un cementerio cerca de Calama (II Región). Un capuchón con rasgos de felino, confeccionado en piel de puma, fue hallado en el cementerio de Cabuza (Núñez 1961: Fig. 4). Este tema, como se verá más adelante, está íntimamente relacionado con la ingestión de substancias psicotrópicas entre varios grupos indígenas de la cuenca del Amazonas.

La tercera categoría de representaciones de felino es el tema del Doble o Alter-ego, que aparece en cinco tabletas (p.e., 2027 Quitor 5; 2442 Quitor 6). En la mayoría de estas tabletas un felino se levanta o descansa sobre una figura humana. Un buen ejemplo del concepto del doble es visto en una de las seis tabletas pertenecientes a la tumba múltiple 2094-2108 de Quitor 5. En esta tableta una figura antropomorfa, que sujeta dos pequeños felinos es coronada por otro felino con grandes colmillos. Esta configuración de motivos, en contextos etnológicos, se refiere a la habilidad del chamán de adquirir características y atributos de felino mientras está bajo la influencia de agentes psicoactivos. Es un tema frecuente en la parafernalia insuflatoria y es común en el Amazonas (Wassén 1967: Fig. 13), y en las tabletas y tubos del Noroeste Argentino (Ambrosetti 1902: Fig. 13; Salas 1945: Fig. 89). Representaciones de Dobles son frecuentes en objetos prehispánicos a través de los Andes, notablemente en la escultura de San Agustín, Colombia (Preuss 1974: Pls. 49, 73).

\section{Aves}

Representaciones ornitomorfas son vistas en 16 tabletas, de las cuales 13 son cóndores (p.e., 5340 Coyo Oriente), y el resto aparentemente halcones (p.e., 3605 Quitor 6; 4027 Coyo Oriente). La asociación de aves con el ajuar insuflatorio es además evidente en los innumerables tubos de inhalación hechos de hueso de ave. Las aves son también una constante en el complejo alucinógeno entre los aborígenes del Amazonas.

Varios otros animales son representados en las tabletas. Lo que son probablemente camélidos, ornamentan sólo cinco tabletas (p.e., 1636 Sequitor Alambrado Oriental; 1816 Catarpe 2), en contraste con su gran importancia en el arte rupestre del norte de Chile.
Ofidios, reptiles relacionados con el uso de alucinógenos en el Amazonas, son representados en sólo dos tabletas de la zona de San Pedro de Atacama (3662 de Quitor 6; 5383 de Coyo Oriente). En una ocasión aparece un armadillo (1300 de Sequitor Alambrado Oriental), en otra están representados dos peces llamados suche (1647 Sequitor Alambrado Oriental).

Una tableta ostenta la representación de un motivo conocido en la literatura como "medio puño" (Sharon y Donnan 1974: 58-59). Con este término se define la posición de una mano con cuatro de sus dedos medio cerrados, o sea con las uñas visibles, y el pulgar erecto a un lado. Esta tableta pertenece a la tumba 3947 del cementerio de Coyo Oriente; fue encontrada con un tubo estilo Tiwanaku. La única otra tableta, con este motivo, proviene del sitio de Niño Korín, Bolivia (Wassén 1972: Pl. 12), y es la reproducción de una mano derecha, mientras la de San Pedro es una mano izquierda.

\section{Representaciones antropomorfas}

Existen aproximadamente unas 41 tabletas con representaciones antropomorfas exclusivamente (p.e., 2800 y 3540 de Quitor 6). Las figuras en estas tabletas no exhiben rasgos zoomorfos ni están asociadas con animales. Entre ellas pueden elaborarse varias categorías. Principalmente esas con apéndices cefálicos cilíndricos, las probables figuras femeninas, e imágenes antropomorfas reclinadas sobre una extensión planiforme.

Las cabezas humanas con apéndices cilíndricos y gorro tipo "fez" ocurren en nueve tabletas (p.e., 2108 Quitor 5; 5203 Sequitor Alambrado Oriental). Estas tabletas parecen representar un individuo, o tal vez un personaje mítico específico, una impresión causada por su invariable figuración en las nueve tabletas. El mismo caso parece suceder en las seis tabletas con representaciones femeninas con los brazos y piernas desplegados. Es posible identificar a esta figura como mujer a través de la tableta 3236 de Quitor 9 (Figura 4), en la cual tres formas romboides ocupan el lugar del pecho y la vagina. Por extensión se podría determinar que en las otras cinco tabletas se pretenden figurar imágenes femeninas $(681 \mathrm{y}$ 1121 Tchecar; 1432 y 1445 Yaye 1; 3292 Yaye 2). La tumba 3236 ha sido fechada por $\mathrm{C}^{14}$ en $1050 \pm 80$ DC, en un contexto con cerámica de tipo Huruquilla (Núñez 1976: 107). Una imagen similar es vista en una tableta procedente de Calilegua (Jujuy, 


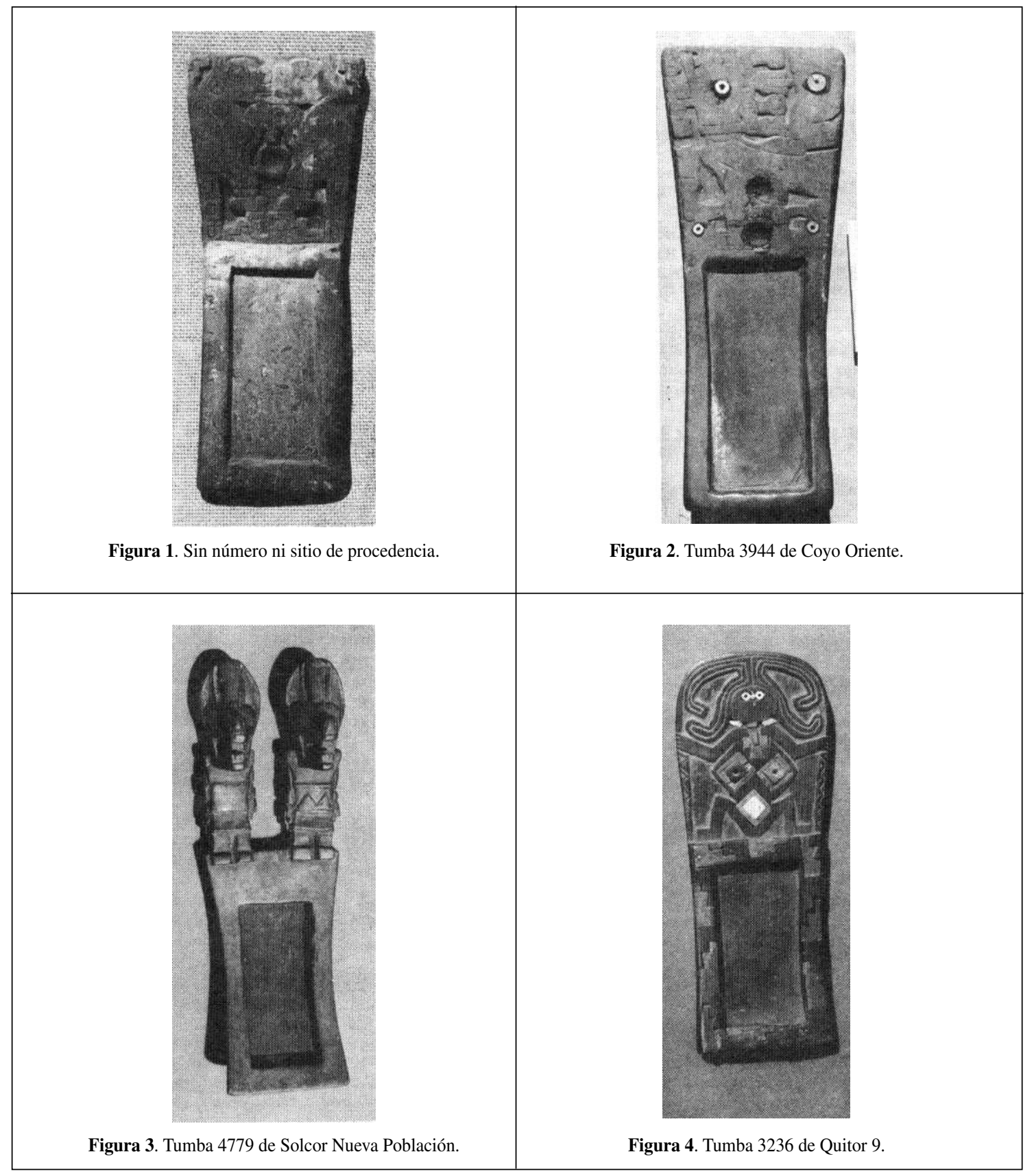

Argentina), ahora en las colecciones del Museum of the American Indian, Heye Foundation, Nueva York ( $\left.{ }^{\circ} 13 / 3657\right)$.

Hay otras tabletas con figuras antropomorfas talladas sobre extensiones planiformes, como por ejemplo esas con un ser humano en posición supina sobre el panel (p.e., 1660 Sequitor Alambrado Oriental; 2477 Quitor 6). En otras tres está representado un personaje como surgiendo de la extensión planiforme (p.e., momia 26 de Solor 3; 1702 Sequitor Alambrado Oriental). Las tres tabletas con este tema en San Pedro están sumamente deterioradas pero, afortunadamente, existe otra, también de San Pedro, en el American Museum of Natural History, Nueva York ( $\mathrm{n}^{\circ}$ 41.0.8911), en muy buenas condiciones (ver Handbook of South American Indians vol. 2: Pl. 132L). Esta nos permite observar detalles ya obliterados en las de San Pedro como las incisiones lineales en estilo Tiwanaku, el cabello de la figura que termina 
en "cabeza de pez", y un elemento escalonado con felinos laterales. También se encuentran en las colecciones del Museo Arqueológico R. P. G. Le Paige cuatro tabletas con dos caras humanas en relieve cada una (p.e., 1321 Quitor 2; 2811 Quitor 6).

Otros tipos de motivos con posible valor iconográfico son los diseños no objetivos, a veces de carácter geométrico, incisos en 12 tabletas (p.e., 1264 y 3689 de Quitor 2; 1947 de Quitor 5; 3020 de Catarpe 2). También deben ser mencionadas ocho tabletas con extensiones planiformes de forma irregular sin diseños incisos o en relieve (p.e., 3618 Quitor 6; 3981 Coyo Oriente), y otras 106 con extensión planiforme regular sin decoración alguna, presentes en casi todos los sitios donde han sido halladas tabletas (p.e., 1446 Yaye 1; 2241 Quitor 5; 3666 Quitor 6).

\section{Conclusiones}

Al estudiar la iconografía de las tabletas de San Pedro de Atacama en su totalidad deben considerarse primeramente las 114 tabletas que no poseen ornamentación alguna. Estas representan aproximadamente un $25 \%$ de las tabletas existentes en la colección del Museo. La casi ausencia de información aparente en este grupo de tabletas contrasta con su prolijidad en las tabletas de estilo Tiwanaku. En varias de estas últimas, como en las tabletas procedentes de las tumbas 1945 de Quitor 5, 4049 y 4141 de Coyo Oriente, el hacedor ha cubierto casi toda la tableta con diseños, una especie de horror vacui como bien lo expresara Wassén (1972: 34) en relación con una tableta de Niño Korín, Bolivia.

La iconografía de las tabletas se expresa en varios temas. Entre ellos están las representaciones de personajes con cetros, figuras genuflexas, individuos con atributos de aves y felinos, y actos de decapitación. Pero entre estos se destacan los individuos con rasgos de felino y/o ave, por su variedad y amplitud de expresión. Debido a limitaciones de espacio, y además por la importancia del tema de la transformación, me concentraré en los atributos felinos y ornitomorfos y su relación con la ingestión de substancias psicoactivas.

\section{El concepto felino}

El motivo felínico es probablemente el elemento iconográfico más importante en las tabletas, y está generalmente asociado con el uso de substancias psicotrópicas entre muchos grupos aborígenes de la cuenca del Amazonas. En muchas ocasiones estos guardan los polvos alucinógenos en huesos de jaguar $\mathrm{y}$, por ejemplo, los chamanes guahibo de los llanos de Colombia se pintan la cara en imitación de las manchas de la piel del jaguar, y llevan tocados y collares hechos de garras y dientes de estos felinos, además de llevar su parafernalia insuflatoria en bolsas hechas de la piel de este animal (Reichel-Dolmatoff 1978: 54-55). Sacerdotes kogi de la Sierra Nevada de Santa Marta, Colombia, usan máscaras en forma de cabeza de jaguar (Preuss 1920: Pls. 30, 31) y se refieren a las sustancias alucinógenas como "la esperma del jaguar" (Reichel-Dolmatoff 1972: 62). Entre los kaxúyana, río Trombetas, Brasil, la tableta es llamada yará-kukúru, o imagen (kukúru) del jaguar mitológico (yará), en una conexión directa de un implemento insuflatorio con el concepto felino (Frikel 1961: 31, 32).

Entre los actuales aborígenes de Colombia una gran cantidad de mitos enfatizan la relación entre el jaguar y los alucinógenos. Los mitos de creación kogi se refieren a una serie de seres-jaguar que nacieron de la madre universal, Kashindúkua; uno de estos seres primordiales podía transformarse en jaguar al introducir en su boca una bola azul, un secreto revelado a él por la madre universal. Dicen los kogi que sus antepasados míticos podían transformarse en jaguar igual que Kashindúkua. Para los kogi ellos son "la gente jaguar, y Kashindúkua es el padre del jaguar. Esta es su tierra" (Reichel-Dolmatoff 1978: 62-64).

La palabra para chamán y jaguar es la misma entre los diferentes grupos tukano de la región del Vaupés (Furst 1968: 156). Los mitos tukano son específicos en los propósitos por los cuales se insufla vihó, un polvo alucinógeno hecho de especies de Anadenantera o virola, entre estos está el de transformarse en jaguar: "Tenían vihó para volverse jaguares y personas. Tenían vihó para volverse dobles" (Reichel-Dolmatoff 1978:114). Los chamanes muisca de Colombia también podían transformarse en jaguar. Un cronista del siglo XVI, Pedro Simón (1892, vol. 2: 268), nos dice: "Son grandes hechiceros, algunos de ellos pueden volverse pumas y jaguares cuando quieren, para conducirse como aquellos".

Peter Furst (1968: 153) relata una historia de los tacana de Bolivia acerca de un jaguar mitológico que instruye a un joven en las artes chamánicas. En este relato un muchacho de 12 años se sube a una 
palma de sayal a recolectar sus frutos cuando fue secuestrado por el gran jaguar alado Iba Bana. El joven desapareció por un año, durante el cual recibió instrucción sobre chamanismo. Cuando regresó a su aldea, entró a la casa ceremonial donde desfalleció como si estuviera muerto. El fue inmediatamente revivido por otros chamanes que le frotaron el cuerpo con un polvo narcótico.

Esta asociación del jaguar con las sustancias psicoactivas no está limitada a los habitantes aborígenes de las Américas. Claudio Naranjo (1973), un psiquiatra chileno, en un estudio sobre los elementos constantes en estados alterados inducidos químicamente, comenta sobre la alta incidencia de imágenes de felinos. Tigres, leopardos o jaguares fueron vistos por siete, de 10 de sus pacientes. Los 10 individuos eran chilenos de la clase media y alta, con ningún conocimiento de mitología nativa. En un caso el jaguar fue percibido como una verdadera personificación. Uno de los pacientes de Naranjo, una mujer de 30 años, escribió en su diario del evento: "Primero muchos tigres. Panteras y toda clase de gatos. Negro y amarillo. Entonces el tigre. El más grande y más fuerte de todos" (Naranjo 1973: 183184, Pl. III).

Estos son solo unos pocos entre los muchos y variados casos de imágenes de jaguar o felino asociadas con el chamanismo y los alucinógenos. Los estudios sobre representaciones de felinos en el mundo prehispánico y entre los aborígenes contemporáneos son numerosos, y una extensa investigación sobre este tópico va más allá de los propósitos de este estudio. Pero en los ejemplos aquí citados es posible observar la estrecha relación existente entre el concepto felino, la búsqueda de la visión y las experiencias extáticas facilitadas por el uso de substancias alucinógenas.

\section{Las aves y los alucinógenos}

Las representaciones ornitomorfas son frecuentes en el equipo insuflatorio prehispánico. La asociación de imágenes de aves con el uso de alucinógenos es un tema común entre los indígenas de la cuenca del Amazonas y su periferia. Además, huesos de pájaros son utilizados muy a menudo como tubos de aspiración y sus plumas y alas son empleadas para facilitar el comienzo de las visiones (Califano 1975: 47). Tubos de inhalación hechos de huesos de ave han sido hallados con las tabletas más antiguas, como en el material excavado en Huaca Prieta, Perú, por Bird (1948). Otro nivel del simbolismo conectado con las aves está relacionado con la adquisición de ciertas de sus cualidades durante el trance extático. Los elementos que parecen ser importantes son la habilidad de volar y la reputada excelente vista de ciertas aves.

Wassén (1965: 28) cita una observación hecha entre los chimane del este de Bolivia. Nos dice que los chimane se frotaban alrededor de los ojos un polvo que contenía ojos de águila pulverizados, para ver mejor durante la cacería. Lévi-Strauss (1948: 38) observó un ritual de curación en el río Guaporé, en el cual el curandero sopló un viento psicoactivo a la nariz del paciente por un tubo que terminaba en una nuez con la forma de la cabeza de un ave con grandes ojos. Preuss narra que durante una visita a los tama (un subgrupo tukano) un chamán bebía yagé, una poción alucinógena hecha de Banisteriopsis sp., y usaba una corona de plumas. Al preguntar Preuss por el propósito de la corona de plumas se le contestó que era para ver mejor durante el trance (cit. en Wassén 1965: 28).

Pedro Simón (1892, vol. 3: 150) relata la historia de un vuelo extático realizado por un chamán muisca:

“... en una ocasión el diablo lo llevó por el aire... y una noche lo llevó a Santa Marta, que está casi a doscientas leguas de allí... y lo volvió a su casa de Ubaque aquella misma noche... nada le espantó tanto como ver la luna tan grande que se le pareció cinco veces mayor que vista de la tierra."

Una asociación felino-ave es mencionada en un mito dosana recopilado por Reichel-Dolmatoff (1978: 115): Los hombres tienen un guacamayo que ayuna y que inhala polvo de vihó con ellos para poder volverse jaguar. Esta combinación de jaguar y pájaro es frecuente en la parafernalia insuflatoria. Por ejemplo, una tableta kaxúyana (Frikel 1961: 8) tiene a dos felinos tallados en su apéndice o mango, y un pájaro en un panel entre la cavidad y el apéndice. Esta juxtaposición felino-ave es vista en la tableta 2189 de Quitor 5, y en la 4141, de Coyo Oriente.

Un estudio de Califano (1975) sobre el chamanismo mataco es importante para esta investigación, debido a su detallada descripción del simbolismo relacionado con las aves. Mataco es el nombre dado a varios grupos aborígenes que ocupan la zona de los ríos Bermejo y Pilcomayo, en Argentina y Paraguay. Los 
mataco aún emplean un polvo alucinógeno hecho de las semillas de cebil (Anadenantera colubrina, var. cebil). El polvo es inhalado para facilitar los viajes del o-'nusek (traducido como "alma" por Califano) del chamán en la forma de un pájaro (Califano 1975: 33). La transformación en ave es propiciada por el toque de una flauta hecha del fémur de un ave yulo. El chamán (jayawú), bajo la influencia del alucinógeno, toca la flauta vigorosamente. Su alma (o-'nusek) abandona el cuerpo a través del tubo de la flauta y comienza su viaje transformado en un ave. Si los viajes del alma no se efectúan con la ayuda de la flauta, el chamán se golpea el pecho con las alas de un halcón. Las alas extraen el $o$-'nusek del cuerpo y lo lanzan al aire (Califano 1975: 47).

La relación de las aves con las sustancias alucinógenas, como hemos visto, tiene una amplia distribución en el continente sudamericano. Esta asociación está expresada en su representación en las tabletas, como esas procedentes de las tumbas 2021 de Quitor 5 y 5340 de Coyo Oriente, y en los tubos de inhalación hechos de hueso de ave. El frecuente uso de motivos ornitomorfos en la parafernalia insuflatoria está basado en la deseada adquisición de ciertos atributos de las aves, como su reputada excelente visión y la habilidad de volar.

El denominador común entre las aves y los felinos es la cualidad de movilidad en diferentes dominios que poseen estos animales. El jaguar, un animal terrestre, puede ser representado como una bestia del fondo del agua, como en los mitos kaxúyana (Frikel 1961: 33), o como un jaguar alado, como en el relato tacana citado por Furst (1968: 153). Los pájaros, además de su supuesta excelente visión, son capaces de volar y de moverse en la tierra. Esta habilidad de desenvolverse en diferentes espacios es una característica cuya necesidad es provocada por los intensos y abruptos cambios causados en la percepción y estados emocionales humanos por los diferentes agentes psicoactivos.

Agradecimientos Quisiera expresar mi agradecimiento al Sr. Agustín Llagostera, por su generosidad y hospitalidad durante mi residencia en San Pedro de Atacama, y a la Comisión Fulbright por el patrocinio de esta investigación.

\section{REFERENCIAS CITADAS}

ALANIS, R., 1947. Material arqueológico de la civilización diaguita. Museo Arqueológico Regional Inca Huasi, La Rioja.

AMBROSETTI, J. B., 1899. Notas de arqueología Calchaquí. Buenos Aires.

1902. Antigüedades calchaquíes. Datos arqueológicos de la Provincia de Jujuy. Imprenta y Casa Editora de Coni y Hermanos, Buenos Aires.

BIRD, J. B., 1948. Preceramic cultures in Chicama and Virú. En A reappraisal of Peruvian archaeology, W. Bennett (Ed.), pp. 21-28. Memoirs of the Society for American Archaeology 4, Menasha.

CALIFANO, M., 1975. El chamanismo mataco. Scripta Etimologica 3 (2): 7-60.

CONKLIN, W., 1971. Peruvian textile fragment from the beginning of the Middle Horizon. Textile Museum Journal 3 (1) $15-24$

DE LAS CASAS, B., 1909. Apologética historia de las Indias. Historiadores de Indias, vol. 1, Nueva Biblioteca de Autores Españoles. Bailly, Bailliere e Hijos Editores, Madrid.

ENGEL, F., 1963. A preceramic settlement on the Central Coast of Peru: Asia, Unit 1. Transactions of the American Philosophical Society New Series vol. 53, part 3, Filadelfia.
FRIKEL, P., 1961. Morí -a festa do rape. Indios kachúyana, rio Trombetas. Boletim do Museu Paraense Emilio Goeldi, Antropología Nova Serie 12: 10-34.

FURST, P. T., 1968. The Olmec Were-Jaguar motif in the light of ethnographic reality. En Dumbarton Oaks Conference on the Olmec, E. Benson (Ed.), pp. 143-178. Washington D. C.

KUBLER, G., 1975. The art and architecture of Ancient America. The Pelican History of Art, Penguin Books, Baltimore.

LEHMANN-NITSCHE, R., 1902. Catálogo de las antigüedades de la Provincia de Jujuy. Talleres de publicaciones del Museo de La Plata, Buenos Aires.

LE PAIGE, G., 1964. El Precerámico en la cordillera atacameña y los cementerios del Período Agroalfarero de San Pedro de Atacama. Anales de la Universidad del Norte 3.

- 1965. San Pedro de Atacama y su zona. Anales de la Universidad del Norte 4.

LEVI-STRAUSS, C., 1948. Tribes of the right bank of the Guaporé river. En Handbook of South American Indians 3: 371-379, Bureau of American Ethnology Bulletin 143, J. H. Steward (Ed.). Washington D. C.

MOSTNY, G., 1958. Máscaras, tubos y tabletas para rapé y cabezas trofeo entre los atacameños. Miscellanea Paul Rivet, Octogenario Dicata 2: 379-392. 
MOSTNY, G. y H. NIEMEYER, 1983. Arte rupestre chileno. Serie el Patrimonio Cultural Chileno, Departamento de Extensión Cultural del Ministerio de Educación, Santiago.

MUNIZAGA, C., 1958. Relatos populares de Socaire. Centro de Estudios Antropológicos, publicación 5, Universidad de Chile, Santiago.

NARANJO, C., 1973. Psychological aspects of the yagé experience in an experimental setting. En Hallucinogens and shamanism, M. Harner (Ed.), pp. 176-190. Oxford University Press, Nueva York.

NUÑEZ, L., 1961. Escultura antropomorfa prehispánica en el norte de Chile. Boletín de la Universidad de Chile 26.

- 1964. El sacrificador. Un elemento cotradicional andino. Noticiario Mensual del Museo Nacional de Historia Natural, VIII (96).

1976. Registro regional de fechas radiocarbónicas del norte de Chile. Estudios Atacameños 4: 74-123.

PANE, R., 1974. Relación acerca de las antigüedades de los indios. Nueva versión con notas, mapas y apéndices por José Juan Arrom. Siglo Veintiuno Editores, México D. F.

POLYKRATES, G., 1960. Einige Holzschnitsereien der KashuiénaIndianer. Folk, Dansk Etnografisk Tidsskrift 2: 115-120.

POSNANSKY, A., 1945. Tihuanacu, the craddle of American man. J. J. Augustin Publisher, Nueva York.

1957. Tihuanacu. Ministerio de Educación, La Paz.

PREUSS, K. T., 1920. Forschungsreise zu den kágaba. Antropos 14-21.

1974. Arte monumental prehistórico. En Excavaciones hechas en el Alto Magdalena y San Agustín (Colombia). Dirección de Divulgación Cultural de la Universidad Nacional de Colombia, Bogotá.
REICHEL-DOLMATOFF, G., 1972. The feline motif in prehistoric San Agustín sculpture. En The cult of the feline. A conference in pre-Columbian iconography. E. Benson (Ed.), Dumbarton Oaks, Washington D. C.

1978. El chamán y el jaguar. Estudio de las drogas narcóticas entre los indios de Colombia. Siglo Veintiuno Editores, México D. F.

SALAS, A. M., 1945. El antigal de Ciénaga Grande (Provincia de Jujuy). Publicaciones del Museo Etnográfico, Serie A.V., Universidad de Buenos Aires, Buenos Aires.

SAWYER, A., 1963. Tiahuanaco tapestry design. The Museum of Primitive Art, Nueva York.

SHARON, D. y C. DONNAN, 1974. Shamanism in Moche iconography. En Ethnoarchaeology, C. Donnan y W. Clewlow (Eds.). Monograph IV. Institute of Archaeology, University of California, Los Angeles.

SIMON, P., 1882-1982. Noticias historiales de las conquistas de tierra firme en las Indias Occidentales, 5 vols. Bogotá.

SPIX, C. y J. MARTIUS, 1823-1831. Reise in Brasilien, 3 vols. Munich.

UHLE, M., 1912. Las relaciones prehistóricas entre Perú y Argentina. XVII Congreso Internacional de Americanistas (1910), pp. 509-540. Buenos Aires.

WASSEN, S. H., 1965. The use of some specific kinds of South American Indian snuffs and related paraphernalia. Etnologiska Studier 28

1967. Anthropological survey of the use of South American snuffs. En Ethnopharmacologic search for psychoactive drugs, D. H. Efron et al. (Eds.), pp. 233-289. Public Health Service Publication 1645, Washington D. C.

1972. A medicine-man's implements and plants in a Tiahuanacoid tomb in highland Bolivia. Etnologiska Studier 32: 7-114. 